\title{
Effect of the house dust mite allergen Der $p 1$ on tryptase release from human mast cells
}

\author{
D.Q. Wang*, Y.Y. Shen*, J.H. Xu and H. Tang \\ Department of Dermatology, Huashan Hospital, Fudan University, Shanghai, \\ China \\ *These authors contributed equally to this study. \\ Corresponding author: H. Tang \\ E-mail: tanghui201511@163.com
}

Genet. Mol. Res. 15 (2): gmr.15018284

Received December 16, 2015

Accepted February 1, 2015

Published July 15, 2016

DOI http://dx.doi.org/10.4238/gmr.15028284

\begin{abstract}
This study aimed to investigate the effects of the house dust mite allergen Der $\mathrm{p} 1$ on the secretion of tryptase from the human mast cell line HMC-1. Flow cytometry was used to determine the expression levels of protease-activated receptor-2 (PAR2) on the surface of HMC-1 cells. HMC-1 cells were treated with Der p 1, SLIGRL-NH (PAR2 agonist), LRGILS-NH ${ }_{2}$ (control peptide for PAR2), or Der $\mathrm{p} 1$ + FSLLRY (PAR2 antagonist), and the tryptase levels were measured using enzyme-linked immunosorbent assay. The biological functions of PAR2 were determined using the calcium green indicator, and intracellular calcium fluorescence intensity in the different groups (Der p 1, SLIGRL-NH ${ }_{2}$, LRGILS- $\mathrm{NH}_{2}$, Der p $1+$ FSLLRY, tryptase, tryptase + FSLLRY, or cell culture medium) was detected by laser scanning confocal microscopy. The mast cells expressed PAR2 receptor on their surfaces. Der p 1 alone induced a significant release of intracellular calcium and tryptase in HMC-1 cells compared with the SLIGRL$\mathrm{NH}_{2}$ treatment group and the control group. The combination of Der p 1 and FSLLRY partly inhibited intracellular calcium and tryptase release in HMC-1 cells compared with the Der $\mathrm{p} 1$ treatment group. Moreover, tryptase induced a significant release of intracellular calcium
\end{abstract}


in the HMC-1 cells. Der $\mathrm{p} 1$ induced HMC-1 cell degranulation and the release of tryptase by activating the PAR2 receptor on the cell surfaces. Tryptase activated the PAR2 receptor and induced intracellular calcium release from the HMC-1 cells in a positive feedback loop.

Key words: House dust mite; Mast cell; PAR2; Tryptase; Der p 1

\section{INTRODUCTION}

Itching is a common symptom of almost all allergic skin diseases, and chronic itching may severely affect a patient's quality of life; its control poses a difficult clinical problem. Human mast cells are a rich repository of neutral proteases, which are critical for the development of itching, and their activation and degranulation result in the generation of various mediators such as histamine and tryptase (Xie and He, 2005). Tryptase is a neutral serine protease with trypsin-like specificity, and is the most abundant mediator stored in mast cell granules. Proteinase-activated receptor-2 (PAR2) belongs to a family of G-protein-coupled receptors. It can be activated by tryptase, which can mediate the induction of itching by regulating the immune system of the skin through neurogenic mechanisms and by participating in pruritogenesis (Ribatti and Ranieri, 2015). House dust mites are one of the most common environmental allergens in allergic skin diseases and other systemic allergic diseases, and present a natural ligand for the PAR2 receptor (Steinhoff et al., 2005) As such, the aim of this study was to investigate the effects of the house dust mite allergen Der $\mathrm{p} 1$ on tryptase release from the degranulating human mast cell line HMC-1 through the PAR2 signaling pathway.

\section{MATERIAL AND METHODS}

\section{Material}

The human mast cell line HMC-1 was kindly donated by Dr. Butterfield's lab (USA); the house dust mite allergen Der p 1 was purchased from Abnova (Taipei city, Taiwan); the tryptase enzyme-linked immunosorbent assay (ELISA) kit and Fluo-3/AM were purchased from the R\&D Company (Lorton, VA, USA); the tryptase was obtained from Promega Corp. (Madison, WI, USA); the peptides SLIGRL-NH (activator peptide for PAR2), LRGILS- $\mathrm{NH}_{2}$ (control peptide for PAR2), and FSLLRY (inhibitory peptide for PAR2) were purchased from Tocris Bioscience Co. (Avonmouth, Bristol, UK); the fluorescein isothiocyanate (FITC)labeled goat anti-mouse PAR2 monoclonal antibody was purchased from Santa Cruz Corp. (Dallas, TX, USA); the fetal bovine serum (FBS), streptomycin, and penicillin were supplied by Gibco (Carlsbad, CA, USA); and the poly-L-lysine was supplied by Sigma-Aldrich (St. Louis, MO, USA).

\section{Cell culture and surface PAR2 expression determination}

HMC-1 cells were inoculated into $75-\mathrm{cm}^{2}$ cell culture flasks and cultured in the cell culture medium supplemented with $0 \%(\mathrm{v} / \mathrm{v}) \mathrm{FBS}, 20 \mathrm{mM}$ 4-(2-hydroxyethyl)-1-piperazine ethane sulfonic acid, $0.01 \%(\mathrm{v} / \mathrm{v})$ 1-thioglycerol, $2 \mathrm{mM}$ L-glutamine, and $1 \%$ streptomycin and penicillin at $37^{\circ} \mathrm{C}$ in a $\mathrm{CO}_{2}$ incubator under sterile conditions with relative humidity 
maintained at 15\%. Log-phase cells were collected, fixed with $20 \mathrm{~g} / \mathrm{L}$ paraformaldehyde for $30 \mathrm{~min}$, washed, and resuspended in phosphate-buffered saline (PBS) containing $10 \mathrm{~g} / \mathrm{L}$ bovine serum albumin (BSA). FITC-labeled goat anti-mouse PAR2 $\mathrm{mAb}(4 \mathrm{mg} / \mathrm{L})$ and the isotype control were added and incubated for $1 \mathrm{~h}$ at $37^{\circ} \mathrm{C}$. After antibody labeling, the cells were washed twice with PBS containing $10 \mathrm{~g} / \mathrm{L}$ BSA, resuspended in PBS, and the PAR2 expression was determined by flow cytometry.

\section{Cell stimulation and tryptase detection}

Log-phase HMC-1 human mast cells were harvested with trypsin, counted using a hemocytometer, and inoculated on 6-well plate $\left(5 \times 10^{5}\right.$ cells per well, three replicates per sample). The cells were treated with $5 \mu \mathrm{g} / \mathrm{mL}$ Der p 1, $100 \mu \mathrm{M}$ SLIGRL-NH ${ }_{2}, 100 \mu \mathrm{M}$ LRGILS-NH ${ }_{2}, 5 \mu \mathrm{g} / \mathrm{mL}$ Der p $1+100 \mu \mathrm{mol}$ FSLLRY, or the cell culture medium for 30 $\min$ at $37^{\circ} \mathrm{C}$. Subsequently, they were harvested and centrifuged at $900 \mathrm{~g}$ for $10 \mathrm{~min}$ at $4^{\circ} \mathrm{C}$. Subsequently, the supernatant was collected and stored at $-80^{\circ} \mathrm{C}$ until required. To investigate the tryptase levels after stimulation, the supernatant obtained by the procedure described above was subjected to tryptase measurements according to the instructions provided with the tryptase ELISA kit.

\section{Intracellular calcium florescence intensity detection}

To investigate the changes in intracellular calcium fluorescence intensity, the human mast cells were seeded on plates, and examined using a laser scanning confocal microscope (LSCM) (Olympus, Japan). HMC-1 cells received the following treatments respectively: 5 $\mu \mathrm{g} / \mathrm{mL}$ Der $\mathrm{p} 1,100 \mu \mathrm{M}$ SLIGRL-NH ${ }_{2}, 100 \mu \mathrm{M}$ LRGILS-NH ${ }_{2}, 5 \mu \mathrm{g} / \mathrm{mL}$ Der $\mathrm{p} 1+100 \mu \mathrm{M}$ FSLLRY, $100 \mathrm{ng} / \mathrm{L}$ tryptase, $100 \mathrm{ng} / \mathrm{L}$ tryptase $+100 \mu \mathrm{M}$ FSLLRY, or the cell culture medium. The cells were incubated with the respective treatment compounds for $30 \mathrm{~min}$ at $37^{\circ} \mathrm{C}$. After treatment, the cells were harvested with $0.25 \%$ trypsin, washed, and dyed with Fluo-3/AM $(10 \mu \mathrm{M})$ in a thermostat-controlled water bath at $37^{\circ} \mathrm{C}$ for $1 \mathrm{~h}$, and shocked every $10 \mathrm{~min}$. After dyeing, the cells were washed a further three times with PBS buffer, and then $2 \mathrm{~mL}$ cell culture medium without FBS and phenol was added. The images of $\mathrm{Ca}^{2+}$ concentration in each cell group were monitored by LSCM. The changes in the intracellular calcium fluorescence intensity before and after treatment were calculated and the obtained data were normalized.

\section{Statistical analysis}

The data are reported as means $\pm \mathrm{SD}$ and the $t$-test was used for inter-group comparisons. $\mathrm{P}<0.05$ indicates a statistically significant difference.

\section{RESULTS}

\section{Surface expression of PAR2 on HMC-1 cells}

In this study, a flow cytometry assay was performed to detect the surface expression of PAR2 on HMC-1 human mast cells. As shown in Figure 1, the results of the flow cytometry analysis revealed the expression of PAR2 receptor on the HMC-1 cell surface. 

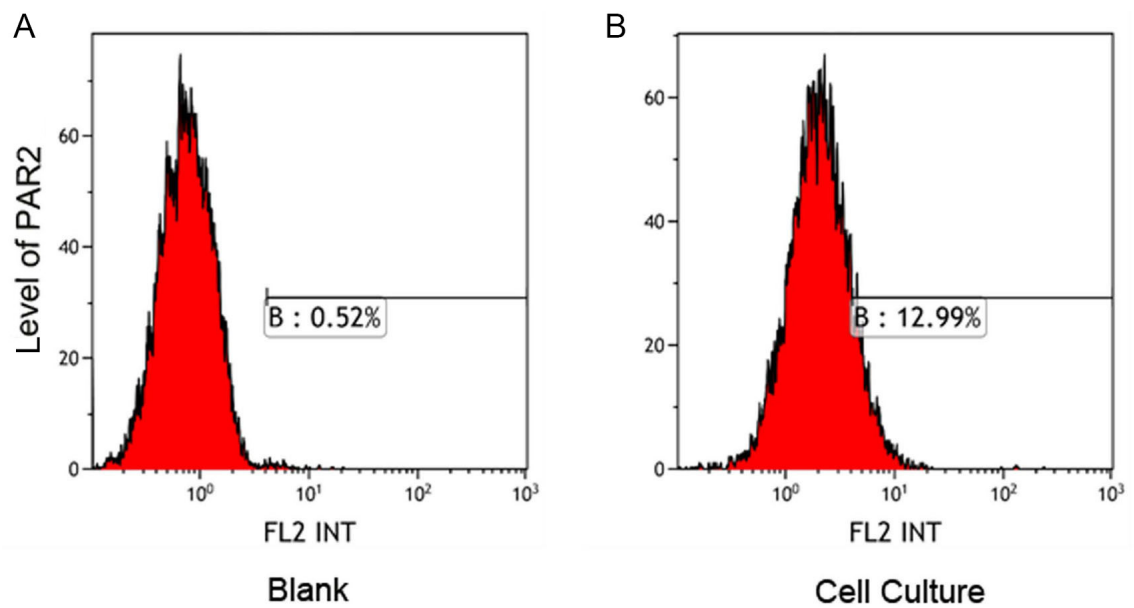

Figure 1. Surface expression of PAR2 on HMC-1 cells. Flow cytometry was performed to detect the surface expression of PAR2 on HMC-1 human mast cells. A. Blank; B. cell culture medium group. Tests were performed in triplicate.

\section{Effect of house dust mite allergen Der $p 1$ on tryptase release from HMC-1 cells}

Tryptase levels after stimulation were measured using ELISA. As shown in Table 1 and Figure 2, the tryptase levels after 30-min treatment of the HMC-1 cells with Der $\mathrm{p} 1$, SLIGRL-NH ${ }_{2}$, LRGILS-NH ${ }_{2}$, or the cell culture medium were $70.40 \pm 1.55,64.45 \pm 1.36$, $24.29 \pm 2.60$, and $31.12 \pm 3.60 \mathrm{ng} / \mathrm{mL}$, respectively. Statistical analyses indicated that the level of tryptase release was significantly higher in the Der 1 treatment group than in the SLIGRL$\mathrm{NH}_{2}$, LRGILS-NH ${ }_{2}$, or cell culture medium treatment groups $(\mathrm{P}<0.05)$. The tryptase level in the HMC-1 cells after treatment with Der p $1+$ FSLLRY was $56.72 \pm 2.66 \mathrm{ng} / \mathrm{mL}$, which was significantly lower than that after Der $\mathrm{p} 1$ treatment alone. Nevertheless, this level was still significantly higher than those of the LRGILS- $\mathrm{NH}_{2}$ and cell culture medium treatment groups $(\mathrm{P}<0.05)$. Taken together, these findings indicate that the house dust mite allergen Der $\mathrm{p} 1$ is an important stimulus for the activation of HMC-1 cells, and the combined use of Der $\mathrm{p} 1$ and FSLLRY could have partly inhibited tryptase release induced by HMC-1 cell degranulation, compared with the Der $\mathrm{p} 1$ treatment group.

Table 1. Tryptase release from HMC-1 cells induced by different stimuli.

\begin{tabular}{l|c}
\hline Stimulus & Tryptase level $(\mathrm{ng} / \mathrm{mL})$ \\
\hline Cell culture medium & $31.12 \pm 3.60$ \\
\hline SLIGRL-NH $2(100 \mu \mathrm{M})$ & $64.45 \pm 1.36$ \\
\hline LRGILS-NH $2(100 \mu \mathrm{M})$ & $24.29 \pm 2.60$ \\
\hline Der p 1 $(5 \mu \mathrm{g} / \mathrm{mL})$ & $70.40 \pm 1.55$ \\
\hline Der p 1 + FSLLRY $(5 \mu \mathrm{g} / \mathrm{mL}+100 \mu \mathrm{M})$ & $56.72 \pm 2.66$ \\
\hline
\end{tabular}

\section{PAR2 activity on the surface of HMC-1 cells following house dust mite and tryptase stimulation}

The induction of intracellular calcium flux and release is an important characteristic of PAR2 activation. The intracellular calcium fluorescence intensity was first measured in HMC- 


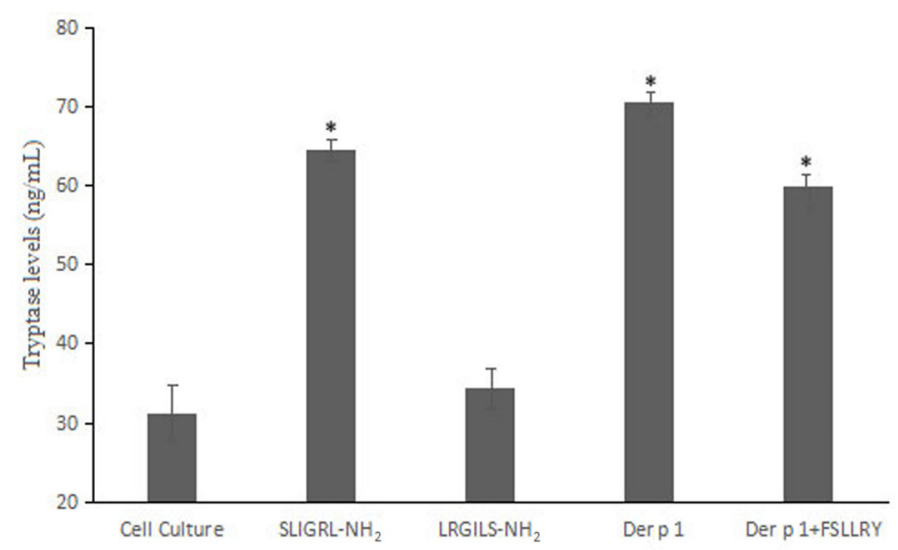

Figure 2. Tryptase release from HMC-1 cells induced by different stimuli. HMC-1 cells were treated with Der $p$ 1, SLIGRL-NH ${ }_{2}$, LRGILS-NH, Der p $1+$ FSLLRY, or cell culture medium. Tryptase levels after stimulation were measured using enzyme-linked immunosorbent assay (ELISA). Experiments were performed in triplicate and data are reported as means $\pm \mathrm{SD}$. $* \mathrm{P}<0.05$, when compared with the control.

1 cells incubated in the cell culture medium, and the data obtained were normalized, processed, and plotted, as shown in Figure 3. After $30 \mathrm{~min}$, the intracellular calcium fluorescence intensity decreased to $72.71 \pm 2.21$ of the original state, indicating a fluorescence-quenching process. After a 30-min treatment with Der p 1, SLIGRL-NH , LRGILS-NH $_{2}$, or tryptase, the intracellular calcium fluorescence intensities of HMC-1 cells were $100.30 \pm 2.37,82.38$ $\pm 2.24,72.77 \pm 3.16$, and $89.95 \pm 2.25 \%$, respectively. Moreover, the intracellular calcium fluorescence intensities in HMC-1 cells after a 30-min treatment with Der p 1 + FSLLRY or tryptase + FSLLRY were $78.63 \pm 3.15$ and $82.60 \pm 3.29 \%$ of the original state, respectively. These data indicate that Der $\mathrm{p} 1$ and tryptase cause significant intracellular calcium flux and release from HMC-1 cells, which could be partly blocked by the PAR2 antagonist FSLLRY.

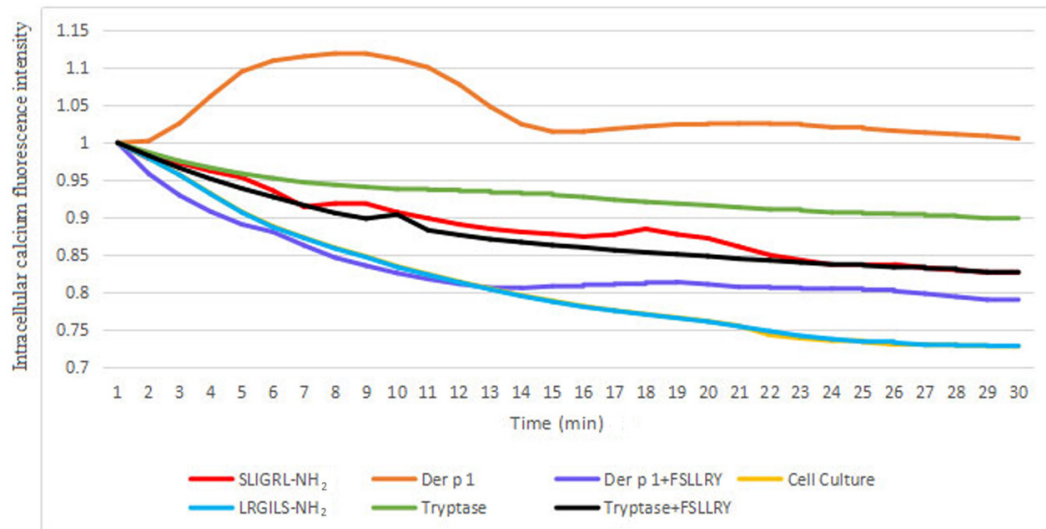

Figure 3. Determination of intracellular calcium fluorescence intensity in HMC-1 cells. HMC-1 cells were treated with Der p 1, SLIGRL-NH ${ }_{2}$, LRGILS-NH ${ }_{2}$, tryptase, Der p 1 + FSLLRY, tryptase + FSLLRY, or cell culture medium. After $30 \mathrm{~min}$, the intracellular calcium fluorescence intensity was measured by laser scanning confocal microscopy (LSCM) and the tests were performed in triplicate. 


\section{DISCUSSION}

Allergic skin diseases are common in dermatology departments. The incidence of allergic skin diseases has been increasing during the last few years, and the majority of patients also have other concurrent allergic diseases such as asthma or allergic rhinitis. Although itching is the common symptom of all clinically common allergic skin diseases, there is no practical and effective treatment for chronic itching. The repeated vicious itch-scratch cycle not only aggravates the skin rash, but also severely affects the mental and physical health and the quality of life of the patient. Therefore, the prevention and treatment of chronic itching is an important area of research.

It has been suggested that inhaled allergens (mainly house dust mites and dust mites) not only induce recurrent attacks of allergic skin diseases, but also induce recurrent attacks and aggravation of asthma and allergic rhinitis (Cho et al., 2012). However, the mechanism by which inhaled allergens participate in the development of allergic diseases, and their correlation with chronic itching are still not fully understood.

PARs are a subfamily of G-protein-coupled receptors comprising four members: PAR1, PAR2, PAR3, and PAR4. PAR2 is widely distributed on the surface of various tissues and cells, mainly human skin mast cells, epithelial cells, activated endothelial cells, muscle cells, neurons, and stellate cells (D’Andrea et al., 2000; Shpacovitch et al., 2002). Previous studies have found that house dust mite extracts induce increased secretion from submucosal glands in the respiratory tract and increase calcium ion influx within pulmonary sensory neurons through activation of PAR2 (Cho et al., 2012; Gu and Lee, 2012). In addition, house dust mite extracts also cause the secretion of IL- 9 by human eosinophils, indicating that the mites participate in the development of the disease through PAR2 activation (Fujisawa et al., 2008). As critical cells involved in the onset of itching, mast cells release histamines and tryptase, both of which are important pruritogenic mediators. Tryptase not only directly activates PAR2 on the surface of neurons, but also activates surface PAR2 on microvascular endothelial cells and keratinocytes. This increases the vascular permeability and upregulates the expression of intercellular adhesion molecules (Steinhoff et al., 2000). Animal experiments have revealed that nafamostat mesylate, a synthetic protease inhibitor, can block tryptase-induced scratching behavior in mice (Ui et al., 2006). Nevertheless, most current studies are only in the in vitro stage of testing, and to date there has been no study on the relevant clinical applications. The combination of tryptase with PAR2 may directly participate in pruritogenesis by acting as the pathway that mediates between mast cells and neurons; the effective inhibition of this pathway may present a potential target for the treatment of chronic itching. We therefore investigated the signaling pathway involving the house dust mite allergen, PAR2, and tryptase activation in mast cells to elucidate the underlying molecular mechanism.

In this study, we first confirmed the presence of PAR2 receptors on the surface of HMC-1 cells by flow cytometry. HMC-1 cells were exposed to different stimuli and ELISA was performed to measure the tryptase levels after stimulation. The independent effect of house dust mite allergen Der $p 1$ on HMC-1 cells apparently caused HMC-1 degranulation with tryptase release at a level that was significantly higher than those induced by PAR2 activators and the normal control group. This finding indicates that the house dust mite allergen Der $p 1$ is an important stimulus for the activation of HMC-1 cells. Compared with the Der $\mathrm{p} 1$ treatment group, the combined use of Der $\mathrm{p} 1$ and FSLLRY can partly inhibit tryptase release induced by HMC-1 degranulation. An important characteristic of PAR2 activation is the induction of 
intracellular calcium flux and release. Through the detection of changes in the intracellular calcium fluorescence intensity in HMC-1 cells, we discovered that Der p 1 and tryptase can cause significant intracellular calcium flux and release from HMC-1 cells, which could be partly blocked by the PAR2 antagonist FSLLRY. Therefore, we concluded that Der $\mathrm{p} 1$ can induce human mast cell degranulation to release tryptase by activating the PAR2 receptor on the surface of human mast cells, but this is not the only pathway of activation. Tryptase may induce the activation of the PAR2 receptor on the surface of mast cells as a positive feedback loop.

By investigating the signaling pathways induced by the house dust mite allergen Der $\mathrm{p} 1$ through PAR2 and tryptase activation in mast cells, this study identified the roles of this pathway in chronic itching and delineated its molecular mechanism. Taken together, our results provide a theoretical basis for new clinical treatments of acute chronic itching.

\section{Conflicts of interest}

The authors declare no conflict of interest.

\section{ACKNOWLEDGMENTS}

Research supported by the National Natural Science Foundation of China (Grant \#81402603) and the Young Scholars of Shanghai Municipal Public Health Bureau (Grant \#20124y032).

\section{REFERENCES}

Cho HJ, Lee HJ, Kim SC, Kim K, et al. (2012). Protease-activated receptor 2-dependent fluid secretion from airway submucosal glands by house dust mite extract. J. Allergy Clin. Immunol. 129: 529-535, 535.e1-535.e5. http://dx.doi. org/10.1016/j.jaci.2011.11.024

D'Andrea MR, Rogahn CJ and Andrade-Gordon P (2000). Localization of protease-activated receptors-1 and -2 in human mast cells: indications for an amplified mast cell degranulation cascade. Biotech. Histochem. 75: 85-90. http://dx.doi. org $10.3109 / 10520290009064152$

Fujisawa T, Katsumata $\mathrm{H}$ and Kato Y (2008). House dust mite extract induces interleukin-9 expression in human eosinophils. Allergol. Int. 57: 141-146. http://dx.doi.org/10.2332/allergolint.O-07-498

$\mathrm{Gu}$ Q and Lee LY (2012). House dust mite potentiates capsaicin-evoked $\mathrm{Ca}^{2+}$ transients in mouse pulmonary sensory neurons via activation of protease-activated receptor-2. Exp. Physiol. 97: 534-543. http://dx.doi.org/10.1113/ expphysiol.2011.060764

Ribatti D and Ranieri G (2015). Tryptase, a novel angiogenic factor stored in mast cell granules. Exp. Cell Res. 332: 157162. http://dx.doi.org/10.1016/j.yexcr.2014.11.014

Shpacovitch VM, Brzoska T, Buddenkotte J, Stroh C, et al. (2002). Agonists of proteinase-activated receptor 2 induce cytokine release and activation of nuclear transcription factor kappaB in human dermal microvascular endothelial cells. J. Invest. Dermatol. 118: 380-385. http://dx.doi.org/10.1046/j.0022-202x.2001.01658.x

Steinhoff M, Vergnolle N, Young SH, Tognetto M, et al. (2000). Agonists of proteinase-activated receptor 2 induce inflammation by a neurogenic mechanism. Nat. Med. 6: 151-158. http://dx.doi.org/10.1038/72247

Steinhoff M, Buddenkotte J, Shpacovitch V, Rattenholl A, et al. (2005). Proteinase-activated receptors: transducers of proteinase-mediated signaling in inflammation and immune response. Endocr. Rev. 26: 1-43. http://dx.doi. org/10.1210/er.2003-0025

Ui H, Andoh T, Lee JB, Nojima H, et al. (2006). Potent pruritogenic action of tryptase mediated by PAR-2 receptor and its involvement in anti-pruritic effect of nafamostat mesilate in mice. Eur. J. Pharmacol. 530: 172-178. http://dx.doi. org/10.1016/j.ejphar.2005.11.021

$\mathrm{Xie} \mathrm{H}$ and $\mathrm{He} \mathrm{SH}$ (2005). Roles of histamine and its receptors in allergic and inflammatory bowel diseases. World $J$. Gastroenterol. 11: 2851-2857. http://dx.doi.org/10.3748/wjg.v11.i19.2851 